Available online on 15.02 .2020 at http://jddtonline.info
Open Access to Pharmaceutical and Medical Research
unrestricted non-commercial use, provided the original work is properly cited

Open $\odot$ Access

Research Article

\title{
Study of In-vitro Antioxidant and Antibacterial activity of leaf extract of Azadirachta indica and Ocimum sanctum in different organic solvents and Cow urine
}

\author{
Nisha Adhikari ${ }^{1}$, Anita Rana ${ }^{1}$, Sangita Oli ${ }^{1}$, Srijana Neupane ${ }^{1}$, Ravin Bhandari ${ }^{1 *}$ and Dirgha Raj Joshi ${ }^{2 *}$ \\ ${ }^{1}$ Department of Pharmacy, Crimson College of Technology, Pokhara University, Butwal-11, Devinagar, Rupandehi, Nepal \\ ${ }^{2}$ College of Pharmacy, Yonsei University, Incheon, Republic of Korea
}

\begin{abstract}
Background: Neem (Azadirachta indica), Tulsi (Ocimum sanctum) and Cow urine (Bos indicus) has been widely used as a therapeutic potential or additive agent in different ethnomedicinal practices as well as modern science also proved its therapeutic potential to treat various diseases and balance the body conditions.

Aims: Alone study on Neem, Tulsi and Cow urine (CU) has been widely performed but this study aims to evaluate the individual as well as synergistic antioxidant and antibacterial activity of Neem, and Tulsi's leaves extract in different organic solvents and Cow urine.

Materials and Methods: Antioxidant activity was carried out by using 2,2-Diphenyl1-picrylhydrazyl (DPPH) radical scavenging activity and the antibacterial activity was tested by the agar disc diffusion method against gram-positive (Staphylococcus aureus) and gram-negative (Escherichia coli, Proteus vulgaris and Klebsiella species) bacteria.

Results: The antioxidant and antibacterial activity is concentration-dependent. The neem extract in chloroform shows the highest ZOI against $S$.

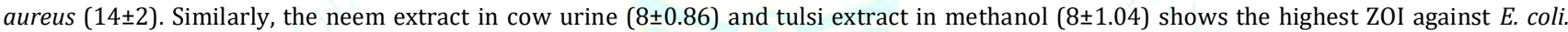
Against $K$. species cow urine is most effective $(9 \pm 0.29)$ followed by neem extract in chloroform and cow urine (8 \pm 0.77$)$. In $P$. vulgaris almost all sample shows ZOI around $7 \mathrm{~mm}$. In synergistic antibacterial study tulsi and neem extract in cow urine shows the highest ZOI against $E$. coli $(12 \pm 1.75)$ and $P$. vulgaris $(10 \pm 1.44)$. The tulsi and neem extract in hexane is not effective against $S$. aureus and $E$. coli but effective in $P$. vulgaris and $K$. species (ZOI $7 \mathrm{~mm}$ ). Tulsi and neem extract in chloroform, methanol, and cow urine show similar ZOI ( 9 mm). In DPPH free radical scavenging activity the methanolic extract of tulsi shows the highest inhibition of free radicle (96.35 \pm 0.001 ), followed by methanolic extract of neem (84.85 \pm 0.042$)$. The fresh cow urine inhibits (25.19 \pm 0.037$)$ followed by neem extract in chloroform (24.53 \pm 0.003$)$, neem extract in cow urine (21.8 \pm 0.012$)$, tulsi extract in chloroform (20.86 \pm 0.047$)$, tulsi extract in hexane (19.5 \pm 0.031$)$, tulsi extract in cow urine (18.33 \pm 0.023$)$ and the least inhibition by neem extract in hexane $(6.74 \pm 0.042)$.

Conclusion: This study concludes that the neem, tulsi and cow urine has good antioxidant and antibacterial activity individually as well as synergistically and the effect is concentration-dependent. Hence the combination formulation could be a better option to study deep in the future.
\end{abstract}

Keywords: Antibacterial, Antioxidant, Azadirachta indica, Ocimum santum, Cow urine, Synergistic

Article Info: Received 26 Nov 2019; Review Completed 19 Jan 2020; Accepted 28 Jan 2020; Available online 15 Feb 2020

Cite this article as:

Adhikari N, Rana A, Oli S, Neupane S, Bhandari R, Joshi DR, Study of In-vitro Antioxidant and Antibacterial activity of leaf extract of Azadirachta indica and Ocimum sanctum in different organic solvents and Cow urine, Journal of Drug Delivery and Therapeutics. 2020; 10(1-s):90-95 http://dx.doi.org/10.22270/jddt.v10i1-s.3908

\section{*Address for Correspondence:}

1 Ravin Bhandari, Department of Pharmacy, Crimson College of Technology, Pokhara University, Butwal-11, Devinagar, Rupandehi, Nepal. Email: ravinbhandari2000@gmail.com

2 Dirgha Raj Joshi, College of Pharmacy, Yonsei University, Incheon, Republic of Korea. Email: djmeropaila121@yonsei.ac.kr

\section{Authors' contributions}

This work was carried out in collaboration with all authors. Authors DRJ and RB designed the study, performed the statistical analysis, wrote the protocol and wrote the first draft of the manuscript. Authors NA lead the research team. Author AR, SO and SN managed the literature searches, collected the urine samples and involved in overall experimental processes. All authors read and approved the final manuscript.

\section{Abbreviations}

DPPH: 2, 2-Diphenyl-1-Picrylhydrazyl ROS: Reactive Oxygen Species

UV: Ultraviolet

mg: MilliGram

ml: Milliliter mcg: MicroGram

g: Gram

$\mu \mathrm{g} / \mathrm{ml}$ : MicroGram per Milliliter

$\mathrm{mg} / \mathrm{ml}$ : MilliGram per Milliliter

$\mathrm{g} / \mathrm{ml}$ : Gram per Milliliter
mM: Milli mole

nm: Nanometer

wt. : Weight

ZOI: Zone of inhibition

CU: Cow urin 


\section{INTRODUCTION}

During the search of a potential therapeutic candidate to heal our body our ancestors did enormous hit and trial throughout the evolution. Various plant species and their different body parts: leaves, root, bark, fruits and other parts are used in our ethnomedicinal practices from the time of human civilization. Many of these ethnomedicinal values of these plants and the animal products are proved by today's scientific experiments.(1) Various research has been published showing the therapeutic potential of Neem(2), Tulsi(3) and Cow Urine. $(4,5)$ The antioxidant and antibacterial activity of neem(6, 7), tulsi(8, 9) and cow urine(5) has also been reported widely.

The neem, tulsi and cow urine has also a great ritual value in Hindu traditions and considered as a panacea for all diseases. The practice of cow urine consumption alone as well as with some herbs and medicinal valued higher plants are practiced in the different ethnic societies. Vedic scripture described the cow as holey animals and considered as a mother. Various cow urine-derived formulations are useful to repel insects to the therapeutic potential.(4) Our previous works studied the altitudinal and climatic variation effect in cow urine for antioxidant and antibacterial activity.(5)

Similarly, the tulsi is known as the queen in the plant, having enormous therapeutic potential. Large group of therapeutic category of tulsi have been studied by previous researchers like antioxidant, antibacterial, chemo-preventive activity, radio-protective activity, antihypertensive, cardio-protective activities, antimicrobial activity, immunomodulatory activity, anti-depressant activity, anti-inflammatory activity, analgesic activity, antipyretic activity, memory enhancer activity, hepatoprotective activity, anti-fertility activity, antidiabetic activity, anti-ulcer activity, and anticoagulant activity, etc.(10) Neem also a very popular therapeutic potential plants whose leaves, bark, seeds, and roots all have great therapeutic value(2).

Some research has been published indicating the combined effect of cow urine and neem $(11,12)$, neem-cow urine extract to control multiple drug resistance(13), the synergistic antimicrobial effect of cow urine and neem(14) Similarly, the combined effect of tulsi extract in cow urine also reported like the antimicrobial effects of water drops developed from cow urine and tulsi(15).

Antibiotic resistance has become a global problem. Whatever new and effective antibiotic was developed they are slowly resistant to the microorganism over time. In this respect, the cow urine and its combination with other herbal extracts might be a better option in the future to fight with these global challenges. So our research team selected all these three: neem and tulsi leaves, and cow urine to check its antioxidants and antibacterial activities. Further, we investigate the mentioned activity in a synergistic form. The detail of plant is available in Plant and people of Nepal by Manandhar NP.(16) The information about cow urine diversified use and its chemical constituents are described by Joshi et al.(4)

\section{MATERIALS AND METHODS}

\subsection{Materials}

All reagents and materials were received from Thermo Fisher Scientific, India Pvt. Ltd. Mumbai. The antibiotic discs (Gentamicin, and Ciprofloxacin) were obtained from Tulip diagnostic Pvt. Ltd. All the needed equipment was used from Pharmacognosy laboratory of Crimson College of Technology (CCT). UV-Visible Spectrophotometer (UV-1800 model; Shimadzu Corporation Pvt. Ltd., China). The fresh local Cow urine was obtained from Kamdhenu Gaushala, Rupandehi, Nepal. The leaves of Neem and Tulsi were collected from the different local areas of the Rupandehi district.

\subsection{Methods}

\subsubsection{Collection of Cow urine, Plant materials, and Test microorganism:}

Before the collection of cow urine, the genital area of cow cleaned properly and collected the morning time urine then filtered and stored in $4{ }^{\circ} \mathrm{C}$ at Pharmacognosy Laboratory of CCT. The plant leaves were collected from the Local area of Rupandehi district, Nepal in September and identified with the help of an expert and also compared with the literature. The Collected plant materials were cleaned with tap water and were then rinsed with distilled water. The remaining water was wiped with the help of a clean cloth. They were then air-dried in shade at room temperature in a wellventilated room. The test microorganism; Staphylococcus aureus (S. aureus), Escherichia coli (E. coli), Proteus vulgaris (P. vulgaris) and Klebsiella species (K. species) were obtained from National Pathology and research center, Butwal, Rupandehi, Nepal.

\subsubsection{Extraction of plant materials:}

The dried leaves were grinded to a fine powder using the home blender. For maceration, $50 \mathrm{~g}$ of dry powder of Neem and Tulsi was taken in $500 \mathrm{ml}$ conical flask and soaked in $250 \mathrm{ml}$ of Chloroform, Methanol, Hexane and Cow urine individually for two days with frequent shaking and stirring. After 2 days the mixture was filtered by using a muslin cloth and the residue again washed with $100 \mathrm{ml}$ of solvent, then finally filtered with Whatman filter paper no.1 and solvents evaporated by using a rotary vacuum evaporator at 20 to 30 ${ }^{\circ} \mathrm{C}$. Then the obtained semisolid was kept aseptically in glass vials and stored at $4{ }^{\circ} \mathrm{C}$.

\subsubsection{Preparation of test solution for antibacterial activity:}

\subsubsection{For individual activity:}

Each plant extract and cow urine was dissolved in DMSO to make a stock solution of $50 \mathrm{mg} / \mathrm{ml}$ and $100 \mathrm{mg} / \mathrm{ml}$. The standard reference drug substance Ciprofloxacin (5mcg) and Gentamicin $(10 \mathrm{mcg})$ were used. DMSO as a negative control.

\subsubsection{For Synergistic Activity:}

$50 \mathrm{mg}$ cow urine extract of Tulsi and $50 \mathrm{mg}$ cow urine extract of Neem mixed and dissolved in DMSO to get 50 $\mathrm{mg} / \mathrm{ml}$ and $100 \mathrm{mg} / \mathrm{ml}$ of stock solution. The same procedure was applied in all extract having similar solvent for synergistic activity.

\subsubsection{Screening of Antibacterial Activity}

As described in our previous work, the antimicrobial activity was checked by disc diffusion method.(5) After subculturing, the entire microorganism $(S$. aureus (grampositive), E.coli, P. vulgaris and K. species (gram-negative)) then they were swabbed into the Agar Petri plates. The 6 $\mathrm{mm}$ diameter test discs were made from filter paper by using the punching machine. Then after proper sterilization of test discs, the $10 \mu \mathrm{l}$ of the test sample was dropped and the standard reference disc (ciprofloxacin- $5 \mathrm{mcg}$, and gentamicin-10mcg) also placed in equidistance in the surface of agar layer. Then the discs allowed to diffuse $(\sim 1 \mathrm{~h})$ and then incubated at $37^{\circ} \mathrm{C}$ for $24 \mathrm{~h}$. All experiments are performed thrice and the antibacterial activity was measured by checking the diameter of zone of inhibition 
(mm) against test organisms. The control discs contain DMSO only.

\subsubsection{Screening of Antioxidant Activity}

DPPH free radical scavenging assay was performed as per our previous experiment.(5) The DPPH solution of $60 \mu \mathrm{M}$ was prepared in DMSO and methanol separately. The positive control, ascorbic acid solution of $100 \mu \mathrm{g} / \mathrm{ml}$ concentration was prepared in DMSO and Methanol separately. For negative control, the DPPH solution $(2 \mathrm{ml})$ is dissolved in methanol $(2 \mathrm{ml})$ and DMSO $(2 \mathrm{ml})$ separately. During the preparation of Stock Solution of the different extract; $100 \mathrm{mg}$ of each extract was dissolved in $100 \mathrm{ml}$ of respective solvent with vigorous shaking. The methanolic extract was dissolved in methanol and the other chloroform, hexane and cow urine extract was dissolved in DMSO. During recording the DPPH Free Radical Scavenging Activity; each sample $(2 \mathrm{ml})$ was added $2 \mathrm{ml}$ of DPPH solution prepared in Methanol and DMSO. Then the vigorously shaken tubes were stored at room temperature in a dark place for $30 \mathrm{~min}$. The sample absorbance was measured at $517 \mathrm{~nm}$ and all samples are recorded thrice, then the inhibition of free radical was calculated by using below formula.

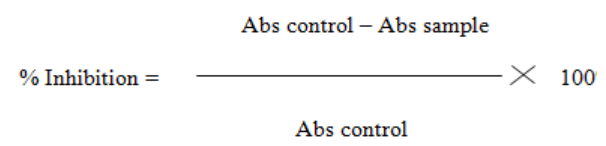

Where,

Abs control $=$ absorbance of DPPH radical + methanol or absorbance of DPPH radical + DMSO

Abs sample $=$ absorbance of DPPH radical +sample extract /standard

\section{RESULTS AND DISCUSSION}

\subsection{Extract yield value:}

The crude extract of leaves of $O$. sanctum and $A$. indica extracted in different solvents i.e. Methanol, Chloroform, Hexane, and Cow urine. The extract yield value was measured by using the following formula and the yield result is presented in table 1.

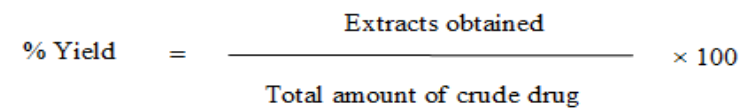

Table 1. Extract yield percentage of different crude sample

\begin{tabular}{|l|l|l|l|}
\hline S.N. & Plant & Leaves Extract in & Yield \% \\
\hline 1. & \multirow{2}{*}{$\begin{array}{l}\text { Ocimum sanctum } \\
\text { (Tulsi) }\end{array}$} & Methanol & 2.6 \\
\cline { 3 - 4 } & & Chloroform & 2.3 \\
\cline { 3 - 4 } & & Hexane & 2.9 \\
\cline { 3 - 4 } 2. & Azadirachta indica \\
& \multirow{2}{*}{\begin{tabular}{l} 
Neem) \\
\cline { 3 - 4 }
\end{tabular}} & Cow urine & 4.2 \\
\cline { 3 - 4 } & & Chloroforman & 3.0 \\
\cline { 3 - 4 } & & Hexane & 2.9 \\
\cline { 3 - 4 } & & Cow urine & 5.3 \\
\hline
\end{tabular}

\subsection{Antibacterial Activity:}

Antibacterial activity of different extract of Neem and Tulsi against four different bacterial strains i.e. S. aureus (grampositive) and E. coli, $P$. vulgaris and $K$. species (gramnegative) were studied by disc diffusion method(17). The clear zone of inhibition (mm) measured and the results of the study are shown in Tables 2 and 3 . The positive control are gentamycin and ciprofloxacin where the control disc contains DMSO only. Table 2 shows the individual activity whereas table 3 presents the synergistic activity. The ZOI was found to be increased with increasing concentration of extract samples with some exceptions. In table 2, the cow urine extract of tulsi and neem both shows good ZOI against all four microbes except the neem cow urine extract against $S$. aureus at $50 \mathrm{mg} / \mathrm{ml}$ concentration. The fresh cow urine diluted (table 2, entry 9) has no ZOI in all microbes but the directly used fresh cow urine without dilution (Table 1, entry 10) shows effectiveness against all microbes (7-9 mm). Neem extract in chloroform (table 1, entry 6) and hexane (table 1, entry 7) looks highly effective with comparison to standard gentamycin and ciprofloxacin against $S$. aureus. 
Table 2: ZOI of Neem and Tulsi extracts in different solvent and fresh cow urine individually.

\begin{tabular}{|c|c|c|c|c|c|c|}
\hline \multirow[t]{2}{*}{ S. N. } & \multirow[t]{2}{*}{ Extract } & \multirow{2}{*}{$\begin{array}{c}\text { Conc. } \\
(\mathrm{mg} / \mathrm{ml})\end{array}$} & \multicolumn{4}{|c|}{$\mathrm{ZOI}(\mathrm{mm})$ in respective Microorganism } \\
\hline & & & S. aureus & E. coli & P. vulgaris & K. species \\
\hline \multirow[t]{2}{*}{1} & \multirow[t]{2}{*}{ Tulsi (Methanol) } & 100 & $8 \pm 0.5$ & $8 \pm 1.04$ & $7 \pm 0.29$ & - \\
\hline & & 50 & - & $7 \pm 0.29$ & $6 \pm 0.5$ & $5 \pm 0.29$ \\
\hline \multirow[t]{2}{*}{2} & \multirow[t]{2}{*}{ Tulsi (Chloroform) } & 100 & - & - & - & $7 \pm 0.5$ \\
\hline & & 50 & - & - & $7 \pm 0.29$ & $7 \pm 0.29$ \\
\hline \multirow[t]{2}{*}{3} & \multirow[t]{2}{*}{ Tulsi (Hexane) } & 100 & - & - & - & $7 \pm 0.29$ \\
\hline & & 50 & $4 \pm 0.25$ & - & - & $7 \pm 0.21$ \\
\hline \multirow[t]{2}{*}{4} & \multirow[t]{2}{*}{ Tulsi (Cow urine) } & 100 & $7 \pm 0.29$ & $6.5 \pm 0.29$ & $7 \pm 0.29$ & $7 \pm 0.29$ \\
\hline & & 50 & $7 \pm 0.29$ & $6 \pm 0.29$ & $7 \pm 0.29$ & $7 \pm 0.29$ \\
\hline \multirow[t]{2}{*}{5} & \multirow[t]{2}{*}{ Neem (Methanol) } & 100 & - & - & - & $7 \pm 0.5$ \\
\hline & & 50 & - & - & - & $6 \pm 0.29$ \\
\hline \multirow[t]{2}{*}{6} & \multirow[t]{2}{*}{ Neem (Chloroform) } & 100 & $14 \pm 2$ & $7 \pm 0.67$ & $7 \pm 0.59$ & $8 \pm 0.77$ \\
\hline & & 50 & $12 \pm 2.08$ & - & $7 \pm 0.51$ & - \\
\hline \multirow[t]{2}{*}{7} & \multirow[t]{2}{*}{ Neem (Hexane) } & 100 & $11 \pm 0.77$ & - & $7 \pm 0.29$ & - \\
\hline & & 50 & $10 \pm 0.5$ & - & - & - \\
\hline \multirow[t]{2}{*}{8} & \multirow[t]{2}{*}{ Neem (Cow urine) } & 100 & $7 \pm 0.29$ & $8 \pm 0.86$ & $7 \pm 0.11$ & $8 \pm 0.77$ \\
\hline & & 50 & - & $6.5 \pm 0.29$ & $7 \pm 0.5$ & $7 \pm 0.5$ \\
\hline \multirow[t]{2}{*}{9} & \multirow[t]{2}{*}{ Fresh Cow urine $\quad$ (Extract) } & 100 & - & - & - & - \\
\hline & & 50 & - & - & - & - \\
\hline 10 & Fresh Cow Urine (direct use) & & $8 \pm 0.77$ & $7 \pm 0.77$ & $7 \pm 0.5$ & $9 \pm 0.29$ \\
\hline \multirow[t]{2}{*}{11} & \multirow[t]{2}{*}{ Gentamycin } & 100 & $9 \pm 0.11$ & $10 \pm 0.29$ & $18 \pm 0.59$ & $20 \pm 0.67$ \\
\hline & & 50 & $9 \pm 0.59$ & $10 \pm 0.11$ & $18 \pm 0.67$ & $21 \pm 0.59$ \\
\hline \multirow[t]{2}{*}{12} & \multirow[t]{2}{*}{ Ciprofloxacin } & 100 & $13 \pm 0.29$ & $19 \pm 0.59$ & $23 \pm 0.11$ & $18 \pm 0.77$ \\
\hline & & 50 & $13 \pm 0.59$ & $19 \pm 0.67$ & $23 \pm 0.29$ & $20 \pm 0.11$ \\
\hline
\end{tabular}

$(-)=$ absence of inhibition zone

The table 3, shows the antimicrobial activity of combination extract in different solvents and cow urine. The synergistic activity looks better than the individual extract. Except the tulsi and neem extract in hexane are not effective against $S$. aureus and E. coli (table 3, entry 3). All other ZOI are from 6 to $12 \mathrm{~mm}$. The tulsi and neem extract in cow urine is better than all other (table 3, entry 4). So the synergistic study shows the broad spectrum of activity.

Table 3. ZOI of Neem and Tulsi extracts in different solvent and fresh cow urine synergistically.

\begin{tabular}{|c|c|c|c|c|c|c|}
\hline \multirow[t]{2}{*}{ S.N. } & \multirow[t]{2}{*}{ Extracts } & \multirow{2}{*}{$\begin{array}{l}\text { Concentration } \\
(\mathrm{mg} / \mathrm{ml})\end{array}$} & \multicolumn{4}{|c|}{ Zone of inhibition (mm) in respective microorganism } \\
\hline & & & S. aureus & E. coli & P. vulgaris & K. species \\
\hline \multirow[t]{2}{*}{1.} & \multirow{2}{*}{$\begin{array}{l}\text { Tulsi and Neem } \\
\text { (Methanol) }\end{array}$} & 100 & $9 \pm 0.77$ & $7 \pm 0.29$ & $9 \pm 0.76$ & $6.5 \pm 0.29$ \\
\hline & & 50 & $8 \pm 0.77$ & $6.5 \pm 0.5$ & $7 \pm 0.77$ & $6.1 \pm 0.29$ \\
\hline \multirow[t]{2}{*}{2.} & \multirow{2}{*}{$\begin{array}{l}\text { Tulsi and Neem } \\
\text { (Chloroform) }\end{array}$} & 100 & $9 \pm 0.5$ & $8 \pm 0.87$ & $8 \pm 0.77$ & $8 \pm 0.58$ \\
\hline & & 50 & $8 \pm 0.77$ & $8 \pm 0.04$ & $7 \pm 0.5$ & $7 \pm 1.04$ \\
\hline \multirow[t]{2}{*}{3.} & \multirow[t]{2}{*}{ Tulsi and Neem (Hexane) } & 100 & - & - & $7 \pm 0.5$ & $7 \pm 0.5$ \\
\hline & & 50 & - & - & $6.5 \pm 0.29$ & $7 \pm 0.29$ \\
\hline \multirow[t]{2}{*}{4.} & \multirow[t]{2}{*}{ Tulsi and Neem (Cow Urine) } & 100 & $9 \pm 0.77$ & $12 \pm 1.75$ & $10 \pm 1.44$ & $8 \pm 0.58$ \\
\hline & & 50 & $8 \pm 0.5$ & $8 \pm 0.77$ & $9 \pm 0.77$ & $8 \pm 0.58$ \\
\hline \multirow[t]{2}{*}{5.} & \multirow[t]{2}{*}{ Gentamycin } & 100 & $9 \pm 0.11$ & $10 \pm 0.29$ & $18 \pm 0.59$ & $20 \pm 0.67$ \\
\hline & & 50 & $9 \pm 0.59$ & $10 \pm 0.11$ & $18 \pm 0.67$ & $21 \pm 0.59$ \\
\hline \multirow[t]{2}{*}{6.} & \multirow[t]{2}{*}{ Ciprofloxacin } & 100 & $13 \pm 0.29$ & $19 \pm 0.59$ & $23 \pm 0.11$ & $18 \pm 0.77$ \\
\hline & & 50 & $13 \pm 0.59$ & $19 \pm 0.67$ & $23 \pm 0.29$ & $20 \pm 0.11$ \\
\hline
\end{tabular}


Some previous study also shows the combined effect of cow urine and neem $(11,12)$, synergistic antimicrobial effect of cow urine and neem(14), neem-cow urine extract to control multiple drug resistance(13), and antimicrobial effects of water drops developed from cow urine and tulsi etc.(15) Many study are performed showing various therapeutic potential of cow urine and cow urine derived formulations and in Vedic scripture to our recent Ayurveda practices cow urine signifies it's potential effect $(4,5)$. Here the better effect with cow urine extract could be from the addition of the effect of cow urine.

\subsection{Antioxidant Activity:}

The antioxidant activity of all the different extract samples is measured by the DPPH radical scavenging method(18) and the percentage inhibition in different concentration are measured are shown in table 4. Ascorbic acid in DMSO and Methanol are as a positive control. The higher sample concentration shows a high percentage of free radical inhibition. Except for the extract in methanol (table 4, entry 1 and 5) all other samples are prepared in DMSO. Tulsi (in methanol) shows good inhibition (96.35\%) nearly comparable to standard ascorbic acid (methanol) (97\%). Where the neem in methanol also shows good inhibition (84.85\%). With comparison to standard ascorbic acid in DMSO (table 4, entry 10), fresh cow urine shows good inhibition (25.2\%), other neem in chloroform (24.5\%), neem in cow urine $(21.8 \%)$, tulsi in chloroform (20.86\%), tulsi in cow urine $(18.3 \%)$ and tulsi in hexane $(19.5 \%)$. The neem extract in hexane shows the least inhibition of free radical $(6.7 \%)$ but the tulsi extract in hexane is satisfactory $(19.5 \%)$. To support our antioxidant results previously also several antioxidant activities of neem(6, 19-21), tulsi(9, 22-24) and cow urine(5, 25-27) are studied. The synergistic antioxidant activity of tulsi, ginger, tea, and black pepper is studied by Gupta et al.(28)

Table 4: Antioxidant activity of neem and tulsi leaves extract and Ascorbic Acid

\begin{tabular}{|c|l|l|l|l|l|}
\hline S.N. & \multicolumn{1}{|c|}{ Extract } & \multicolumn{3}{c}{$\%$ inhibition in their respective concentration of extract } \\
\hline \multirow{2}{*}{1.} & & $\mathbf{1 0 0} \boldsymbol{\mu g} / \mathbf{m l}$ & $\mathbf{1 0} \boldsymbol{\mu g} / \mathbf{m l}$ & $\mathbf{1} \mathbf{g} / \mathbf{m l}$ & $\mathbf{0 . 1} \mathbf{\mu g} / \mathbf{m l}$ \\
\cline { 2 - 6 } & Tulsi (Methanol) & $\mathbf{9 6 . 3 5} \pm \mathbf{0 . 0 0 1}$ & $82.66 \pm 0.006$ & $68.41 \pm 0.035$ & $56.97 \pm 0.044$ \\
\hline 2. & Tulsi(Chloroform) & $20.86 \pm 0.047$ & $15.6 \pm 0.227$ & $6.88 \pm 0.228$ & $3.78 \pm 0.039$ \\
\hline 3. & Tulsi (Hexane) & $19.5 \pm 0.031$ & $9.94 \pm 0.009$ & $3.83 \pm 0.003$ & $3.05 \pm 0.017$ \\
\hline 4. & Tulsi (Cow Urine) & $18.33 \pm 0.023$ & $11.56 \pm 0.021$ & $8.86 \pm 0.039$ & $5.65 \pm 0.005$ \\
\hline 5. & Neem (Methanol) & $84.85 \pm 0.042$ & $38.85 \pm 0.089$ & $19.29 \pm 0.07$ & $17.97 \pm 0.024$ \\
\hline 6. & Neem (Chloroform) & $24.53 \pm 0.003$ & $22.42 \pm 0.002$ & $10.34 \pm 0.024$ & $6.41 \pm 0.003$ \\
\hline 7. & Neem (Hexane) & $6.74 \pm 0.042$ & $5.38 \pm 0.006$ & $1.99 \pm 0.019$ & $0.61 \pm 0.018$ \\
\hline 8. & Neem (Cow Urine) & $21.8 \pm 0.012$ & $15.84 \pm 0.028$ & $12.8 \pm 0.036$ & $9.72 \pm 0.17$ \\
\hline 9. & Fresh Cow Urine & $25.19 \pm 0.037$ & $16.02 \pm 0.024$ & $9.33 \pm 0.032$ & $6.55 \pm 0.029$ \\
\hline 10. & Ascorbic Acid (DMSO) & $28 \pm 0.071$ & $26 \pm 0.024$ & $25 \pm 0.018$ & $6 \pm 0.029$ \\
\hline 11. & Ascorbic Acid (Methanol) & $97 \pm 0.013$ & $93 \pm 0.001$ & $84 \pm 0.109$ & $64 \pm 0.034$ \\
\hline
\end{tabular}

\section{CONCLUSION}

This study reveals that the potential antimicrobial activity of neem, tulsi, and cow urine individually as well as synergistically extracted in different organic solvents (methanol, chloroform, and hexane) and cow urine. Also, the antioxidant test of all extracts and cow urine signifies its free radical scavenging potency. Tulsi and neem extract in cow urine shows the best activity in the synergistic study against $E$. coli and $P$. vulgaris. Except for some exception, the antibacterial and antioxidant activity are concentrationdependent; activity increased with higher concentration. Neem extract in chloroform shows the highest activity against $S$. aureus. Tulsi extract in methanol shows better scavenging activity than neem extract in methanol. With the evidence of antioxidant and antibacterial activity of neem and tulsi from this study in different organic solvents and cow urine, it can be suggested for further deep research to study the detailed mechanism of synergistic activity, chemical process involved, ratio of chemical constituents in different solvent systems and the mechanism of action to affect the bacterial cells including the role of antioxidant and antibacterial in disease curing.
Notes: The authors declare no competing financial interest.

\section{Acknowledgement}

We heartily acknowledge Crimson College of Technology, Butwal, Nepal for providing necessary things to carry out this research.

\section{REFERENCES}

1. Rates SMK. Plants as source of drugs. Toxicon. 2001; 39(5):603-13.

2. Subapriya R, Nagini S. Medicinal properties of neem leaves: a review. Current Medicinal Chemistry-Anti-Cancer Agents. 2005;5(2):149-56.

3. Garg P, Sardana S. Pharmacological and therapeutic effects of Ocimum sanctum. European journal of pharmaceutical and medical research. 2016; 3(8):637-40.

4. Joshi DR, Adhikari N. Benefit of cow urine, milk, ghee, curd and dung versus cow meat. Acta Scientific Pharmaceutical Sciences. 2019; 3(8):169-75.

5. Joshi DR, Aryal P, Chaudhary MK, Yadav SP, Rawal P, Adhikari $\mathrm{N}$, et al. Study of in-vitro Antioxidant and Antibacterial Activity 
of Cow Urine from Different Altitudinal and Climatic Region of Nepal. Microbiology Research Journal International. 2019:1-8.

6. Sithisarn P, Supabphol R, Gritsanapan W. Antioxidant activity of Siamese neem tree (VP1209). Journal of Ethnopharmacology. 2005; 99(1):109-12.

7. Francine U, Jeannette U, Pierre RJ. Assessment of antibacterial activity of neem plant (Azadirachta indica) on Staphylococcus aureus and Escherichia coli. J Med Plants Stud. 2015; 3(4):8591.

8. Mishra P, Mishra S. Study of antibacterial activity of Ocimum sanctum extract against gram positive and gram negative bacteria. Am J Food Technol. 2011; 6(4):336-41.

9. Kelm M, Nair M, Strasburg G, DeWitt D. Antioxidant and cyclooxygenase inhibitory phenolic compounds from Ocimum sanctum Linn. Phytomedicine. 2000; 7(1):7-13.

10. Pandey G, Madhuri S. Pharmacological activities of Ocimum sanctum (tulsi): a review. Int J Pharm Sci Rev Res. 2010; 5(1):61-6.

11. Gupta M. Efficacy of neem in combination with cow urine against mustard aphid and its effect on coccinellid predators. 2005.

12. Boomathi N, Sivasubramanian P, Raguraman S. Biological activities of cow excreta with neem seed kernel extract against Helicoverpa armigera (Hübner). Annals of Plant Protection Sciences. 2006; 14(1):11-6.

13. Rajapandiyan K, Muthu G, Ranjit A. Azadirachta indica-cow urine extract, a novel controlling agent towards Clinically significant Multi Drug Resistant Pathogens. Journal of Applied Pharmaceutical Science. 2011; 1(10):17.

14. Vats S, Miglani K. Synergistic antimicrobial effect of cow urine and Azadirachta indica on infectious microbes. International Journal of Pharmaceutical Sciences and Research. 2011; 2(7):1781

15. Distillate Motos. Antimicrobial Activity of Water Drop Developed From Mixture of Tulsi (Ocimum Sanctum) Distillate and Cow Urine Distillate.

16. Manandhar NP. Plants and people of Nepal: Timber press; 2002.

17. Bauer A. Antibiotic susceptibility testing by a standardized single disc method. Am J clin pathol. 1966; 45:149-58.
18. Molyneux $P$. The use of the stable free radical diphenylpicrylhydrazyl (DPPH) for estimating antioxidant activity. Songklanakarin J sci technol. 2004; 26(2):211-9.

19. Ghimeray AK, Jin C-W, Ghimire BK, Cho DH. Antioxidant activity and quantitative estimation of azadirachtin and nimbin in Azadirachta Indica A. Juss grown in foothills of Nepal. African Journal of Biotechnology. 2009; 8(13).

20. Rinaldi F, Hanieh PN, Longhi C, Carradori S, Secci D, Zengin G, et al. Neem oil nanoemulsions: characterisation and antioxidant activity. Journal of enzyme inhibition and medicinal chemistry. 2017; 32(1):1265-73.

21. Nahak G, Sahu R. Evaluation of antioxidant activity of flower and seed oil of Azadirachta indica A. juss. Journal of Applied and Natural Science. 2011; 3(1):78-81.

22. Ramesh B, Satakopan V. Antioxidant activities of hydroalcoholic extract of Ocimum sanctum against cadmium induced toxicity in rats. Indian Journal of Clinical Biochemistry. 2010; 25(3):307-10.

23. Gupta S, Mediratta PK, Singh S, Sharma K, Shukla R Antidiabetic, antihypercholesterolaemic and antioxidant effect of Ocimum sanctum (Linn) seed oil. 2006.

24. Joshi R. Chemical composition, in vitro antimicrobial and antioxidant activities of the essential oils of Ocimum gratissimum, 0 . sanctum and their major constituents. Indian journal of pharmaceutical sciences. 2013; 75(4):457.

25. Jarald E, Edwin S, Tiwari V, Garg R, Toppo E. Antioxidant and antimicrobial activities of cow urine. Global journal of pharmacology. 2008; 2(2):20-2.

26. Sachdev DO, Gosavi DD, Salwe KJ. Evaluation of antidiabetic, antioxidant effect and safety profile of gomutra ark in Wistar albino rats. Ancient science of life. 2012; 31(3):84.

27. Gosavi D, Sachdev D, Salwe K. Immunomodulatory and antioxidant effect of gomutra ark in rats. J Mahatma Gandhi Inst Med Sci. 2011; 16:37-41.

28. Gupta RK, Chawla P, Tripathi M, Shukla AK, Pandey A. Synergistic antioxidant activity of tea with ginger, black pepper and tulsi. International Journal of Pharmacy and Pharmaceutical Sciences. 2014; 6(5):477-9. 